\title{
Medical Savings Accounts: experiências internacionais no contexto adverso da individualização do risco*
}

\author{
Medical Savings Accounts: international experiences in an adverse scenario of risk \\ individualization
}

Pedro Paulo de Salles Dias Filho'

'Doutorando em Saúde Pública pela Escola Nacional de Saúde Pública da Fundaçăo Oswaldo Cruz (ENSP/FIOCRUZ) - Rio de Janeiro (RJ), Brasil. Servidor do Banco Central do Brasil - Rio de Janeiro (RJ), Brasil. pp.salles@uol.com.br
RESUMO $O$ estudo oferece uma visão do produto conta-poupança em saúde. Informa suas características e implantação em sistemas nacionais de saúde. Trata-se de uma revisão da literatura relativa às Medical Savings Accounts (MSA) com visões distintas sobre a aplicabilidade do produto, para situá-lo no contexto de individualização do risco, tendência de alguns sistemas de Bem-Estar operantes no mundo. Encontram-se detalhadas as experiências das MSA em Cingapura, nos Estados Unidos e na África do Sul. O resultado da revisão da literatura permite concluir que o produto é inadequado no que se refere ao controle de custos e aponta para os riscos de sua má utilização, com impactos desfavoráveis na saúde pública.

PALAVRAS CHAVE: Planos de saúde; Conta-poupança em saúde; Individualização do risco; Responsabilização.

ABSTRACT This study provides an overview of the product health savings accounts. It provides information about its features and implantation in national health systems. It deals with a revision on literature related to Medical Savings Accounts (MSA) with different views on the applicability of the product, in order to place it into the context of risk individualization, current trends in some operating systems of Living Well in the world. In the course of the work we can find detailed experiences of MSA in Singapore, USA and South. The outcome of the literature review shows the inadequacy of the product concerning the control of health costs, and points out its misuse that might cause unfavorable impacts in public health.

KEYWORDS: Health-plan; Health savings accounts; Risk-individualization; Health-accountability.
As opiniões expressas neste trabalho são exclusivamente do autor e não refletem, necessariamente, a visão do Banco Central do Brasil. 


\section{Caracterização do produto}

As Medical Savings Accounts (MSA), ou Health Savings Accounts (HSA), como são conhecidas nos Estados Unidos (EUA), têm sido alvo de estudos do economista conservador John C. Goodman, fundador e atual CEO do National Center for Policy Analysis (NCPA), um think tank baseado em Dallas (Texas, EUA). Para definir o produto, é oportuno começar pela caracterizaçáo do próprio Goodman (1996), feita em uma conferência em 1996, cuja referência foi publicada em artigo anos depois:

Medical Savings Accounts oferecem às pessoas a oportunidade de migrarem de um seguro-saúde convencional, com baixas franquias, para um plano que cobre gastos catastróficos, mas com elevadas franquias, que permite depositar parcela dos prêmios em contas-poupança pessoais. Essas contaspoupança são utilizadas para cobrir gastos rotineiros em saude, assim como as despesas com prevenção, enquanto a apólice de elevada franquia cobre as despesas de maior monta. [No caso dos planos coletivos] os empregados e suas familias pagam todas as contas médicas até o limite de suas franquias, utilizando-se de suas contas-poupança [em saúde] pessoais, e uma vez esgotados os saldos nessas contas, pagam por meio do desembolso direto. Já o seguro [catastrófico] cobre todos os gastos acima da franquia. Eventuais saldos remanescentes nas contaspoupança ao final do ano podem ser sacados livremente, ou mantidos nas contas-poupança rendendo juros.

Exemplifica com um caso em que \$ 2 mil são depositados, todos os anos, nas contas-poupança pelo empregador, enquanto o empregado depara-se com uma franquia de \$3 mil. Assim, os primeiros $\$ 2$ mil de despesas médicas são cobertos pelo saldo da MSA, os \$ 1 mil subsequentes são pagos via desembolso direto, e o plano ou seguro-saúde paga todas as despesas acima de $\$ 3$ mil, ou, melhor dizendo, a partir de $\$ 3$ mil. Se as despesas anuais em saúde forem inferiores a \$2 mil, o empregado pode gastar o saldo em bens e serviços não médicos, ou poupá-lo nas respectivas MSA (GOODMAN, 1996, p. 145).

Para Goodman (1996), como o trabalhador está tendo gastos do próprio bolso, ele terá os incentivos para controlar os custos em saúde. As MSA não apenas resultam em poupança financeira para o empregado, mas também permitem aos empregadores reduzirem suas despesas gerais com atenção à saúde dos empregados. Estima-se que os custos com atenção à saúde das empresas no modelo MSA situam-se em torno de $12 \%$ menores do que aqueles relacionados a um plano de saúde convencional.

Para Shortt (2002), em tese, assume-se que, ao tornar os consumidores responsáveis pelas consequências financeiras do consumo indiscriminado de serviços de saúde, eles serão motivados a procurar o melhor preço disponível e a melhor qualidade do cuidado possível, providos por prestadores competitivos, todavia o autor duvida disso, conforme será tratado no item 'Discussão'.

Em contraste com as formas coletivas de financiamento da seguridade, capazes de lidar contra os riscos das doenças, como o seguro-social, o sistema das Medical Savings Accounts determina que o risco deverá ser coberto por cada indivíduo (SCHREYÖGG, 2004, p. 690).

Ainda segundo Schreyögg (2004), uma vez que as despesas com o cuidado em certos tipos de tratamento frequentemente excedem a capacidade financeira dos indivíduos, as MSA normalmente são oferecidas combinadas com um seguro-saúde para riscos catastróficos.

Em geral, essa conta-poupança, em saúde, é normalmente administrada pela própria seguradora, através de um fundo-doença (sickness fund). Serviços não reembolsados ou não cobertos pelo seguro de risco catastrófico são automaticamente debitados dos saldos acumulados nessas contas-poupança. Os saldos eventualmente remanescentes permanecem rendendo a uma dada taxa de juros. 


\section{Experiências internacionais}

O produto MSA entrou em operação inicialmente em 1984, em Cingapura. O modelo cingapuriano, denominado 3M (Medisave, Medishield e Medifund), tem operação estatal.

Nos EUA, a primeira legislação do Congresso datava de 1995 e concedia isenção fiscal aos depósitos feitos nas MSA. Foi vetada por Bill Clinton. No ano seguinte, finalmente, a isenção fiscal foi estendida a dois programas-piloto de MSA, benefício que atendeu a 750 mil pequenos empregadores e autônomos, como parte da Health Insurance Portability and Accountability Act, de 1996, e a 390 mil beneficiários do Medicare, a partir da Balanced Budget Act, de 1997 (GOODMAN, 1996).
Além de Cingapura e dos EUA, a África do Sul adotou o programa, ainda nos anos 1990. A China operou, também nos anos 1990, dois programas-piloto em duas grandes regióes metropolitanas (GOODMAN, 1996; SCHREYÖGG, 2004). Esse caso não será tratado neste estudo.

Segundo Schreyögg (2004), na Europa, o assunto tem sido discutido sob o ponto de vista prático e sob uma perspectiva teórica. No Brasil, a discussão ainda é bastante preliminar, circunscreve-se aos sindicatos corporativos.

O quadro a seguir compara a operação das MSA em Cingapura, na África do Sul e nos Estados Unidos. Essas experiências, além da chinesa, serão detalhadas no próximo item.

Quadro 1. Comparativo dos diversos sistemas de MSA, segundo características

\begin{tabular}{|c|c|c|c|}
\hline \multirow[b]{2}{*}{ Critérios } & \multicolumn{3}{|c|}{ Países } \\
\hline & Cingapura & África do Sul & EUA \\
\hline Objetivos & $\begin{array}{l}\text { Prevenção do risco moral; } \\
\text { reserva financeira para a maior } \\
\text { idade }\end{array}$ & $\begin{array}{l}\text { Redução de custos; prev. risco } \\
\text { moral; Inclusão de peq. empresas } \\
\text { e autônomos }\end{array}$ & $\begin{array}{l}\text { Redução de custos; prev. Risco } \\
\text { moral; expansão do seguro } \\
\text { privado }\end{array}$ \\
\hline Adesão & Compulsória & Voluntária & Voluntária \\
\hline $\begin{array}{l}\text { Cálculo das contribuições } \\
\text { ou prêmios }\end{array}$ & Percentual da renda salarial & Baseada em risco atuarial & Risco atuarial \\
\hline Coberturas & $\begin{array}{l}\text { Ambulatorial custo-intensiva; } \\
\text { hospitalar de baixo custo }\end{array}$ & $\begin{array}{l}\text { Serviços médicos e ambulatoriais } \\
\text { até a franquia }\end{array}$ & Integral até a franquia \\
\hline $\begin{array}{l}\text { Financiamento do seguro } \\
\text { (risco catastrófico) }\end{array}$ & $\begin{array}{l}\text { Fundo de Seguro-saúde } \\
\text { (Fundo Central da Previdência) }\end{array}$ & Seguro privado & Seguro privado \\
\hline Administração & Estatal & Privada & Privada \\
\hline Rendimentos / juros & 2,5 a $4 \%$ a.а. & Até $7,5 \%$ & Variável \\
\hline População coberta & 2,7 mi (84\%) & 1,6 a 2 mi (4-5\%) & Menos de 300 mil $\left(^{*}\right)$ \\
\hline
\end{tabular}

Fonte: SCHREYÖGG, Jonas. Demographic development and moral hazard: health insurance with medical savings accounts. The Geneva Papers on Risk and Insurance, Hants, UK, v. 29. n. 4, p. 689-704, oct. 2004 


\section{O modelo de Cingapura}

Trata-se de experiência consolidada de MSA. Cingapura é uma cidade-estado de 3,3 milhóes de habitantes (dados do ano 2000), que teve implantado em 1984 o modelo Medisave, compulsório, com coberturas hospitalares de média complexidade e ambulatoriais de alto custo, representando, portanto, a parcela relativa ao modelo MSA (SHORTT, 2002).

A parte relativa ao seguro catastrófico está representada pelo Medishield, adotado em 1990. Em 1993, foi criado o Medifund, de caráter filantrópico, destinado a cobrir as despesas dos indigentes. Não obstante, embora existam clínicas que obtêm subsídios do governo para o cuidado dos mais pobres, o financiamento da maior parte dos gastos ambulatoriais com esse grupo tem origem no desembolso direto (SHORTT, 2002).

No Medisave, todo trabalhador contribui para uma MSA pessoal, gerida pelo governo. As contribuiçóes variam entre 6\% (pessoas até 35 anos) e $8 \%$ da renda mensal (faixa acima de 45 anos), divididos igualitariamente entre empregadores e empregados. Os autônomos pagam a contribuição integral. Existe um teto de contribuição para pessoas de renda mais alta. Assim, esse indivíduo contribui para o Medisave até atingir o saldo de S\$17 mil (em moeda local - ano-base: 2000). As contribuiçóes são isentas de imposto e rendem juros (BARR, 2001).

Segundo Barr (2001), existem restriçóes para a cobertura de procedimentos no âmbito do Medisave. Pacientes com saldos insuficientes (na MSA) para a cobertura de certos gastos comprometem suas contribuições futuras ao Medisave (MSA), isto é, esses saldos serão utilizados para o pagamento das contas médicas pendentes. Tal diferimento não é permitido em certos tipos de tratamento, tais como procedimentos de reprodução assistida, diálise, radioterapia, quimioterapia e tratamento com AZT, isto é, devem ser pagos no ato, diretamente pelo paciente.

$\mathrm{O}$ mesmo ocorre no caso do Medishield. O seguro entra em ação quando a conta hospitalar supera a franquia individual. Ainda assim, o valor pago pelo seguro corresponde a $80 \%$ do gasto, devendo o paciente arcar com a diferença. Independentemente dessas restriçóes, também não haverá cobertura do Medishield para cuidados/procedimentos de longo prazo e caros, como diálises, quimio e radioterapias (BARR, 2001).

$\mathrm{O}$ Medifund tem caráter filantrópico, todavia também cobre poucos procedimentos. Sua fonte de recursos deriva de um fundo constituído em 1993, com contribuição inicial de 200 milhóes de dólares cingapurianos adicionada por capitalizaçóes anuais de 100 milhóes, até ter atingido, no ano 2000, um saldo de S\$ 700 milhôes. Apenas os juros decorrentes desse fundo é que são distribuídos anualmente às clínicas, a título de subsídio, para fazer frente ao atendimento filantrópico, o que significa que poucos procedimentos são gratuitos (BARR, 2001).

Segundo Shortt (2002), dados de 1995 indicam que o desembolso direto representou $57,7 \%$ do total do gasto de saúde em Cingapura, enquanto a parcela relativa às MSA (Medisave) representou apenas 8,5\%.

Para Shortt (2002), ao se estabelecer a responsabilização dos consumidores de serviços médicos, no sentido de controlarem os custos a partir dos pesados desembolsos diretos no financiamento à saúde, em tese, esperava-se que o modelo das MSA iria, de fato, controlar os custos em Cingapura, mas isso não aconteceu. Os custos per capita seguiram subindo desde a implantação do Medisave, resultado da crescente utilização de tecnologias caras nos hospitais privados e do consequente aumento dos preços dos serviços prestados. Em resposta, o governo, a partir de 1993, iniciou pesados controles restritivos à oferta de serviços nos hospitais públicos e passou a restringir serviços no âmbito do programa $3 \mathrm{M}$.

Após a reforma de 1993, recursos do Medisave não podem mais ser utilizados para cobrir alguns tipos de cuidado obstétrico, assim como a assistência hospitalar de longo prazo. Por seu turno, o Medishield (seguro voltado para os gastos catastróficos) não cobre doenças e lesões pré-existentes, incluindo derrame, doenças coronarianas, obstrução pulmonar crônica ou câncer (SHORTT, 2002, p.160).

Nesses termos, na visão de Barr (2001), não há evidências de que o sistema de MSA de Cingapura tenha conseguido controlar custos de saúde. $\mathrm{O}$ autor afirma que o controle de custos no sistema de saúde da ilha refere-se mais à influência de um governo forte, 
que faz controle via contenção da oferta e do consumo de serviços de saúde. Shortt (2002) segue na mesma direção ao afirmar que o programa MSA de Cingapura aparenta contribuir pouco para o controle de custos, que resulta basicamente das fortes restriçóes do lado da oferta de serviços.

$\mathrm{Na}$ visão do governo local, a filosofia do financiamento da atenção à saúde em Cingapura "é baseada na responsabilidade individual, associada aos subsídios governamentais a fim de manter os cuidados básicos em saúde acessíveis" [em termos de preços] (BARR, 2001).

Para Barr (2001), a verdadeira lição da experiência cingapuriana reside na sua negação: não há uma 'bala mágica' para o financiamento à saúde. Quanto mais um sistema de saúde é efetivo em conter custos, ou, ainda, eficiente em transferir responsabilidades [do governo], maior a probabilidade de esse sistema ser inequitativo.

\section{O modelo sul-africano}

O sistema nacional de saúde sul-africano é público, contudo, nos últimos anos, a adesão a seguros-saúde cresceu, e $20 \%$ da população passou a ter cobertura de saúde privada. Na África do Sul, o modelo de MSA concorre com os produtos tradicionais de asseguramento em saúde. O sistema de MSA tem operação privada e opera combinado com seguro para cobertura das despesas com tratamentos crônicos e hospitalizaçóes custointensivas. São as chamadas despesas não discricionárias. Para as discricionárias, o usuário utiliza seu saldo da MSA (SCHREYÖGG, 2004).

O saldo depositado nas MSA para os gastos discricionários são, em média, equivalentes a US\$ 1,5 mil. Os saldos das MSA são remunerados a 7,5\% a.a., e, se for necessário um adiantamento da conta, os juros serão também de 7,5\%. Os recursos são geridos diretamente pelas seguradoras e aplicados no mercado de capitais (SCHREYÖGG, 2004).

Segundo Schreyögg (2004), algumas seguradoras introduzem em seus produtos MSA um sistema de pontuação correspondente a procedimentos utilizados em saúde preventiva, que podem servir de descontos em compras diversas de serviços não médicos.
Exemplificando-se o caso da operadora Discovery Health, que pontua uma senhora acima de 45 anos que faz um mamograma com 2,5 mil pontos. Acumulando-se pontos, pode-se adquirir descontos em produtos náo médicos, p.e., com 60 mil, compra-se uma passagem aérea com $92 \%$ de desconto em relação ao preço cheio da mesma.

Segundo Schreyögg (2004), o sistema de MSA sul-africano detém $50 \%$ da fatia do mercado de seguro privado em saúde do país. Söderlund e Hansl (2000) discutem que o conceito de MSA aplicado na África do Sul é, a priori, atraente para pessoas jovens e saudáveis, e, portanto, acaba por gerar uma seleção adversa.

Por ter estudado o tink tank do Texas, o NCPA não concorda que as MSA da África do Sul selecionem jovens, afirmando que aqueles assegurados com MSA não são necessariamente mais saudáveis do que os assegurados em planos de saúde tradicionais, com cobertura compreensiva. O estudo do NCPA concluiu, ainda, que despesas incorridas em procedimentos médicoambulatoriais nos grupos segurados por MSA foram, de fato, menores do que aquelas relativas ao grupo segurado por apólices tradicionais, compreensivas (MATISONN, 2000). O estudo foi conduzido por Shaun Matisonn, atual Chefe do Gerenciamento de Riscos da seguradora Discovery Health, da África do Sul.

\section{HSA nos EUA}

A ideia de MSA nos EUA, originalmente, foi concebida por John C. Goodman e pelo NCPA. Em um ambiente de elevados custos médicos observados ao longo dos anos, o conceito foi desenvolvido para reduzir o risco moral dos contratantes, em particular, para os casos de gastos médico-ambulatoriais. Goodman e Musgrave conduziram um estudo, em 1992, que concluiu que um aumento nas franquias dos seguros-saúde pode levar a uma sensível redução nos prêmios (SCHREYÖGG, 2004; GOODMAN; MUSGRAVE, 2000).

O ponto focal da proposta de Goodman era o estabelecimento de incentivos fiscais para que cidadãos comuns pudessem efetuar depósitos voluntários em suas MSA, ofertadas pelas seguradoras associadas a um 
seguro-saúde para gastos catastróficos, com elevadas franquias (SCHREYÖGG, 2004).

O programa foi implantado em 1996, durante a administração Clinton, sob a forma de um piloto, na esteira da legislação da Health Insurance Portability and Accountability Act (HIPAA) (Lei no 104-191, de 21/08/96). As MSA poderiam ser oferecidas durante quatro anos (até 2000), prorrogáveis por mais dois (final de 2002), para um número limitado de contas (750 mil). As franquias variavam entre US\$1,5 mil e US\$ 2,25 mil para planos individuais, e entre US\$ 3 mil e US\$ 4,5 mil para planos familiares. Foi estabelecido, no piloto, que os montantes máximos a serem aportados nas MSA, para obtenção da isenção fiscal, deveriam ficar entre $65 \%$ e $75 \%$ das franquias. A administração Bush estendeu o piloto até o final de 2003 e levantou praticamente todas as restrições existentes até então (SCHREYÖGG, 2004).

Em 2004, o programa foi liberado para comercialização generalizada sob o nome de Health Savings Accounts (HSA). Os recursos das HSA podem ser utilizados para a cobertura de quaisquer despesas médicas, sendo que os saques com esses propósitos não são taxados pelo imposto de renda. Os fundos não utilizados permanecem na HSA obtendo rendimentos isentos de imposto; podem ser acumulados anualmente e são portáteis, isto é, em caso de mudança de seguradora, o participante leva os saldos consigo para a outra HSA escolhida (CANNON, 2006).

Desde que as HSA tornaram-se disponíveis, em janeiro de 2004, o número de americanos que aderiram voluntariamente ao produto atingiu a casa dos três milhôes. Isto é, houve, basicamente, uma migração do seguro-saúde tradicional para o seguro-saúde de elevada franquia, compatível com uma HSA. O número de pessoas que compraram uma HSA diretamente é menor e não pode ser quantificado. No total, observadores estimaram em 6 milhóes o número de beneficiários até 2008, com saldos acumulados nas HSA estimados em US\$ 5 bilhôes; e, para 2010, US\$ 25 milhóes, detendo US\$ 75 bilhôes em ativos (CANNON, 2006).

É importante fazer aqui um parêntese: a grande crise financeira de 2008-2009 gerou uma elevação da taxa de desemprego nos EUA, ocasionando exclusão de jovens e pessoas de baixa renda dos planos de saúde, com consequente encarecimento dos preços das apólices.

O custo do asseguramento em saúde nos EUA, não é novidade, tem crescido a taxas elevadas. Jovens e pessoas saudáveis estáo deixando os planos em funçáo dos preços das apólices. Vale relembrar trechos do polêmico aumento anunciado para os preços dos planos individuais da operadora californiana WellPoint, no início de 2010:

Nos EUA é preocupante a recente notícia de ameaça de aumentos abusivos de preços da operadora Anthem Blue Cross of California, subsidiária da WellPoint Inc., que em janeiro de 2010 anunciou pretensóes de reajustar os preços de 800.000 clientes de planos individuais em $39 \%$, a partir de $1^{\circ}$ de março de 2010.

[...] A operadora, representada pelo chefe de sua 'consumer business unit' Brian Sassi, afirma que os 'preços em geral dos seguros saúde estão aumentando graças a fatores como elevação dos custos com prestadores e ao envelhecimento populacional, no entanto a recessão acelerou os aumentos de custos a niveis ainda maiores no mercado de planos individuais da Califórnia.

A presidente da American Health Insurance Plans (AHIP), Karen Ignagni, afirmou que os prêmios dos planos individuais estão subindo por causa dos custos médicos, que 'estão nas nuvens', e porque jovens e pessoas saudáveis estão deixando a cobertura privada, segundo ela por causa da situação atual. (SALLES DIAS FILHO, 2010, p. 151-153).

Essas informaçóes ilustram um cenário em que empresas americanas estão - e já há muito tempo com dificuldades para honrar os custos assistenciais de suas forças de trabalho, e em busca de custos menores, através da responsabilização dos trabalhadores. Juntos, esses fatores têm impulsionado o mercado das HSA nos Estados Unidos. Segundo o relatório de Cannon (2006, p. 2), do Cato Institute, um think tank liberal ${ }^{1}$, 
Em teoria, HSA tornarão os pacientes consumidores mais prudentes de cuidados em saúde, porque consumidores são mais custo-conscientes quando gastam o próprio dinheiro. Os pacientes tenderão a perguntar mais sobre os custos e beneficios das diversas opçóes de tratamento, como, por exemplo a troca de um remédio de marca por um genérico.

\section{Discussão: os prós e contras da adoção das MSA}

A crítica mais comum rebatida pelos defensores das MSA é a de que as HSA ou MSA beneficiam somente os mais ricos e saudáveis. De outro lado, as críticas mais duras apontam que as MSA não só são ineficientes na sua proposta de reduzir os custos, mas podem ser nocivas ao controle da saúde das pessoas (CANNON, 2006).

Os defensores das MSA, em resposta àqueles que alardeiam que o interesse por MSA estaria restrito aos mais saudáveis, afirmam que pessoas de todas as idades têm aderido ao produto. Assim, uma vez atraindo a população mais idosa, as MSA deveriam também ser atraentes para as pessoas, em tese, menos saudáveis.

A American Academy of Actuaries também apontou um ganho [apenas] para os saudáveis ao questionar que o dinheiro economizado na migração de um plano ou apólice de baixa franquia para um de elevadas franquias seria tão modesto que apenas esses iriam se beneficiar financeiramente com as MSA (GOODMAN, 1996, p. 152).

Durante 12 anos, a RAND Corporation conduziu o RAND Health Insurance Experiment, no qual estudou aleatoriamente duas mil famílias participantes de diferentes tipos de coberturas de saúde. Algumas famílias recebiam assistência à saúde gratuita, outras recebiam coberturas com compartilhamento de custos (no caso dos planos tradicionais com franquias e coparticipação), incluídos os casos em que as coberturas se pareciam com o tipo ofertado pelo produto MSA.

Os resultados de saúde das pessoas que possuíam planos de saúde com elevadas franquias não foram, de maneira geral, piores do que os daqueles que possuíam qualquer outro tipo de cobertura, apesar de terem 'consumido’ bem menos serviços médicos. Os investigadores escreveram:

nossos resultados demonstraram que um aumento de $40 \%$ na quantidade de serviços de saúde obtidos gratuitamente pelas pessoas teve pouco ou nenhum efeito sobre o status de saúde desses adultos. (CANNON, 2006, p. 5).

Com isso, Cannon (2006) pretende demonstrar que existe pouca evidência para sugerir que os planos de saúde com franquias resultem em piores resultados de saúde para o grupo dos menos saudáveis.

Sob o ponto de vista econômico, os críticos das MSA argumentam que o produto permite aos empregadores transferir custos de benefícios de saúde para os trabalhadores. Ao invés de proverem coberturas compreensivas aos empregados, os empregadores estão mudando para planos MSA, empurrando para as costas dos trabalhadores boa parte dos seus custos assistenciais.

Os eventuais ganhos obtidos com menores gastos, não fica claro por quem, estão sendo absorvidos. Segundo Schreyögg (2004), um estudo da RAND Corporation calculou a queda nas despesas de assistência à saúde durante o programa-piloto de MSA, situando-a entre $0 \%$ e $13 \%$.

Dados da consultoria Towers-Perrin (2008), em sua pesquisa anual sobre os custos em saúde, efetuada em 2007 e publicada no ano seguinte, demonstram que os custos médicos mensais médios dos Consumer-driven Health Plans (dentre esses, as MSA), em 2007, são relativamente menores do que todos os planos de saúde combinados entre $16 \%$ e $19 \%$, dependendo da cobertura, se individual ou familiar, conforme indica o Quadro 2.

' Em sua home page, o Cato Institute se autodenomina uma instituição de pesquisa de políticas públicas dedicada aos princípios da liberdade individual, do governo limitado, dos mercados livres e da paz, ou, in verbis: The Cato Institute is a public policy research organization - a think tank - dedicated to the principles of individual liberty, limited government, free markets and peace. Its scholars and analysts conduct independent, nonpartisan research on a wide range of policy issues. Disponível em: http://www.cato. org/about.php. Acesso em: 25 abr. 2011. 
Quadro 2. Custo médico mensal médio segundo o tipo de plano e coberturas (USA-2008) - Em US\$ (preços correntes)

\begin{tabular}{|l|l|l|l|}
\hline \multirow{2}{*}{ Tipos de planos } & \multicolumn{3}{|c|}{ Coberturas } \\
\cline { 2 - 5 } & Apenas empregado & Empregado e um dependente & Familiar \\
\hline Todos os planos & 385 & 792 & 1119 \\
\hline $\begin{array}{l}\text { Planos PPO (Preferred } \\
\text { Provider Organizations) }\end{array}$ & 394 & 810 & 1141 \\
\hline $\begin{array}{l}\text { Planos POS (Point-of-service } \\
\text { plans) }\end{array}$ & 416 & 843 & 1202 \\
\hline $\begin{array}{l}\text { HMO (Health Maintenance } \\
\text { Organizations) }\end{array}$ & 378 & 778 & 1103 \\
\hline $\begin{array}{l}\text { ABHP - PI. de Saúde } \\
\text { baseados em contas- } \\
\text { poupança(*) HRA }\end{array}$ & 354 & 721 & 1011 \\
\hline $\begin{array}{l}\text { ABHP - PI. de Saúde } \\
\text { baseados em contas- } \\
\text { poupança(*) HSA }\end{array}$ & 315 & 642 & 936 \\
\hline
\end{tabular}

Fonte: Adaptado de: TOWERS-PERRIN. Health Care Cost Survey. 2008. Disponível em: <http://www.towersperrin.com/tp/getwebcachedoc?webc=HRS/USA/2008/200801/ hccs_2008.pdf> Acesso em: 25 abr. 2011.

Notas:

(') PPO - planos de livre escolha

(2) POS - Mix entre livre escolha e rede credenciada

$\left(^{3}\right) \mathrm{HMO}$ - Planos que operam com rede, a exemplo das medicinas de grupo

(*) Account-based Health Plans, duas modalidades: HRA (Health Reimbursement Account) e HSA (Health Savings Account)

O survey de 2008 traz a inflação médica dos planos empresariais, em relação ao ano anterior, dentre todos os tipos de planos relacionados no Quadro 3.

Quadro 3. Inflação médica dos planos empresariais (EUA 2007)

\begin{tabular}{|l|l|}
\hline Categorias de planos & Variação de custos anual \\
\hline Todos os planos combinados & $6 \%$ \\
\hline PPOs & $6 \%$ \\
\hline POSs & $8 \%$ \\
\hline HMOs & $7 \%$ \\
\hline HRAs & $7 \%$ \\
\hline HSAs & $7 \%$ \\
\hline
\end{tabular}

Fonte: Adaptado de: TOWERS-PERRIN. Health Care Cost Survey. 2008. Disponível em: <http://www.towersperrin.com/tp/getwebcachedoc?webc=HRS/USA/2008/200801/ hccs_2008.pdf> Acesso em: 25 abr. 2011. 
A conclusão óbvia a que se chega é a de que a inflação médica incide de maneira praticamente igual em todos os tipos de planos de saúde observados. No caso da HSA, ela até supera a inflação geral dos planos. Portanto, o dado da pesquisa desmente que as HSA são capazes de reduzir os custos assistenciais pela força do poder discricionário dos consumidores (consumerdriven plans).

Tudo leva a crer que o pressuposto de que os custos estáo sendo transferidos dos empregadores para os empregados é verdadeiro.

Outros argumentos importantes para a análise dos impactos das MSA estão presentes no estudo de Cannon (2006), sendo de relevância a crítica a seguir: quais seriam os impactos do desenvolvimento das MSA sobre os demais planos?

A conferência de Goodman, de 1996, já trazia tal questionamento. Ele, na ocasião, citou John Burry, chairman das Blue Cross \& Blue Shield de Ohio, o qual havia advertido, ainda nos anos 1990, que as MSA poderiam significar, ao mesmo tempo, vantagens inesperadas para os saudáveis [apólices anuais mais baratas] e a ruína para a estabilidade financeira da indústria de seguros (GOODMAN, 1996, p. 152).

Essa é a questão econômica central, sobre a qual os resultados das diversas pesquisas, surveys e artigos acadêmicos ainda não ofereceram resposta. $\mathrm{O}$ trabalho de Cannon (2006) deixa essa questão em aberto de forma preocupante.

Alguns observadores preveem que as HSA irão causar o aumento dos prêmios nos seguros com cobertura compreensiva (tradicionais). Participantes saudáveis, ao abandonarem o pool em busca da adesão às HSA, deixarão os menos saudáveis na carteira, o que poderia causar a elevação nos prêmios, levando a um movimento seguinte de novas saídas e novos encarecimentos de prêmios (CANNON, 2006, p. 6), podendo ocasionar a chamada 'morte em espiral' de certos planos tradicionais.

Uma explicação teórica desse fenômeno poderia ser dada a partir da visão de Schreyögg (2004), segundo a qual uma gradual introdução das MSA acompanhada de uma correspondente diminuição de parte do sistema custeado por contribuiçôes tradicionais levará a uma redução da influência do pacto intergeracional. Tanto maior a proporção de custos assistenciais fundeados pelas MSA, menores os efeitos da distribuição intergeracional, que, no caso das populaçóes em processo de envelhecimento, levará a uma elevação das despesas assistenciais desse grupo.

Outra questáo controversa relativa ao modelo das MSA refere-se às decisões dos usuários referentes a modalidades de tratamento às quais, em tese, eles deveriam ser submetidos mediante aconselhamento médico. Cannon (2006, p. 12), em seu trabalho, citou uma pesquisa na qual pessoas portadoras de MSA seriam significativamente mais propensas a evitar, a economizar ou a adiar tratamentos de saúde por conta dos custos do que aquelas que optam por coberturas compreensivas tradicionais.

Segundo a pesquisa citada, pessoas portadoras de MSA seriam $50 \%$ mais propensas a questionar os prestadores quanto aos custos das terapias; 33\% estariam propensas a buscar terapias alternativas, e estariam três vezes mais dispostas a buscar tratamentos alternativos mais baratos.

Cannon (2006) aponta, ainda, que, em consequência, uma maior consciência dos custos relativos aos tratamentos induziria os prestadores a atentarem mais para seus preços e para a qualidade dos serviços ofertados. O autor acredita que as MSA, ao tornarem os consumidores mais sensíveis aos custos - uma vez que desembolsam parte das despesas com o autocuidado -, os tornam mais críticos quanto aos tratamentos a que serão submetidos.

Conforme avalia Schelkle (2008), a tendência dominante de liberalização nas economias políticas avançadas está movendo os esquemas de Bem-Estar em direção a uma hibridização, com a aplicação dos princípios de mercado nos esquemas de proteção, representada por uma privatização dos serviços sociais. Noçóes de escolha ou de quase mercados estão sendo introduzidas nesses novos esquemas. Há mais escolha individual e menos formaçóes de 'pools de risco'. Há uma notável ênfase à individualização em detrimento da socialização dos riscos.

O prêmio Nobel de Economia 2008, Paul Krugman, em artigo em sua coluna do New York Times, 
criticou duramente essa postura de tratar pacientes como consumidores de serviços médicos:

E eis minha questão: quando é que se tornou normal, ou, aliás, quando é que se tornou aceitável, se referir a pacientes de serviços médicos como 'consumidores?' A relação entre médicos e pacientes costumava ser considerada como algo de especial, quase sagrado. Agora, politicos e supostos reformistas falam sobre o ato de receber cuidados de saúde como se não diferisse de uma transação comercial [...].

\section{[...] Os Estados Unidos têm o sistema de saúde} com mais 'influência do consumidor', entre os paises avançados, e também apresentam os custos de saúde mais altos, por larga margem, sem que isso resulte em serviços de saúde de qualidade superior à encontrada em outros países nos quais o sistema tem custo mais baixo.

Krugman (2011) conclui seu artigo afirmando que a medicina como escolha do consumidor fracassou onde quer que tenha sido tentada.

Além de reafirmar o fracasso da utilização de produtos consumer-driven, quando se trata de cuidado médico, Krugman traz ao debate a questão subjacente do uso indiscriminado das MSA. Em situaçôes limites, elas carregam o dom de perverter a relação médico-paciente. Imbricados pela financeirização do cuidado, os pacientes tornam-se consumidores que definem as opçóes de tratamento, deixando em segundo plano o aconselhamento médico. Que consequências isso pode ter?

Em testemunho ao Congresso americano, ainda nos anos 1990, John Sturdivant, presidente da Federação de Empregados Estatais (AFL-CIO), declarou que, sob a égide das MSA, os trabalhadores adiariam tratamentos até que se tornassem absolutamente necessários (GOODMAN, 1996, p. 153). Para alguns críticos, evitar ou adiar procedimentos assistenciais hoje poderia resultar em cuidados assistenciais futuros mais custosos ainda, o que tornaria os planos com franquias elevadas uma obtusidade (CANNON, 2006, p. 11).

Para outros, a escolha por MSA acopladas a um seguro catastrófico de elevadas franquias encorajaria os optantes dessa modalidade de produto a serem consumidores mais cautelosos. Segundo Cannon (2006), se os participantes puderem reduzir os prêmios de seus seguros através da contenção do tabagismo, do controle de suas taxas de açúcar no sangue ou de colesterol, dentre outros, mais participantes poderiam fazer o mesmo.

Em nota publicada em periódico brasileiro ${ }^{2}$, essa questão foi abordada: 'Para reduzir o impacto dos custos futuros, os convênios médicos começam a se voltar à prevenção, com estímulo a práticas que reduzam a possibilidade de tratamentos. Alguns exemplos são a prática de atividades físicas e a adoção de hábitos saudáveis'. Segundo empresas, porém, o cliente resiste à prevenção (grifos nossos).

A resistência, portanto, é real, existe, sendo certo que alguns críticos advogam a desconstrução do consenso estabelecido a partir da crise do Estado de BemEstar, que consiste na concepção de uma suposta necessidade e na consequente legitimidade de pensarem-se as políticas atuais de saúde não mais como frutos de um 'pacto sanitário' sobre o direito do cidadão aos cuidados em saúde, e um dever correspondente ao Estado de garanti-las, mas, ao contrário, como um dever do cidadão de ser saudável e um direito do Estado de incentivar, controlar e, eventualmente, sancionar o comportamento daquele cidadão que, por ventura, tivesse práticas denominadas 'não saudáveis' (SCHRAMM, 2006).

Schramm (2006) antecipa uma possível objeção à proposta da bioética da proteção ao apontar os perigos paternalistas e autoritários das atitudes protetoras, visto que estas poderiam tornar-se instrumentos não legítimos de limitação do exercício da autonomia pessoal e, mais ainda, de cerceamento dos assim chamados 'direitos fundamentais', cuja garantia é condição necessária da responsabilização moral do agente pelos seus atos.

${ }^{2}$ FOLHA DE SÃO PAULO. Estratégia: empresas incentivam prevenção. Folha de São Paulo. São Paulo: segunda-feira, 11 de abril de 2011. Mercado. 
Shortt (2002, p. 162) afirma que

a noção de que [com as MSA] os individuos terão um incentivo para adotar hábitos saudáveis para reduzirem seus gastos em saúde não é respaldada por nenhuma evidência.

Afirma que não há evidências de que pessoas detentoras de MSA conseguiram obter maior adequação do cuidado ou mesmo melhor qualidade. De fato, o autor avalia que, em alguns casos, cuidados preventivos necessários poderão ser adiados por aqueles com desejo de aumentar seus saldos nas MSA, levando a custos futuros elevados ante as situaçóes de saúde agravadas pelo adiamento das terapias (SHORTT, 2002).

Segundo esse mesmo autor, as MSA não aparentam ter atingido as suas metas. Ao avaliar as experiências correntes de Cingapura, China e as simulaçóes utilizando-se dos dados do Medicare americano, o autor não recomenda a adoçáo do produto no Canadá, onde é diretor do Centro de Pesquisas de Políticas e Serviços de Saúde da Queen's University (Ontario.). Segundo ele, as MSA "[...] além de não terem controlado custos, podem aumentar as iniquidades em sistemas públicos de saúde" (SHORTT, 2002, p. 159).

Shortt (2002) avalia que, conforme o sugerido pela experiência de Cingapura, as MSA não contribuem para uma distribuição mais equitativa da cobertura, sendo que o produto, quando combinado a incentivos fiscais, é atraente para os mais ricos e saudáveis, deixando as pessoas dependentes do 'pool de risco' em situação de buscar alternativas ainda mais onerosas, ou a ponto de enfrentarem crescentes desembolsos diretos.

Estudo patrocinado pela Organização Mundial da Saúde (OMS) indica que não há evidências claras de que o Medisave de Cingapura tenha, significativamente, reduzido o risco moral e contribuído para conter custos, já que o dispêndio de Cingapura em saúde continuou a crescer mesmo após a introdução das MSA (HANVORAVONGCHAI, 2002).

Hsiao (2001), outro crítico das MSA, afirma que o esquema cingapuriano se utiliza dos cidadáos para promover a constrição dos custos em saúde. Os custos são regulados pelo lado da demanda. O exemplo de Cingapura demonstra que, do lado da oferta, os prestadores competem pelos melhores profissionais médicos e pelas mais sofisticadas tecnologias custo-intensivas; a competição via preços é secundária.

\section{Considerações finais}

A implantação das MSA nos países que a adotaram tinha como mote a redução de custos ante a responsabilização do indivíduo. Acreditava-se nas escolhas racionais das pessoas influenciando o controle dos preços e da qualidade dos serviços, isto é, confiava-se na hipótese de que consumidores são custo-conscientes quando gastam o próprio dinheiro. No entanto, as experiências mostraram que o produto foi inefetivo no quesito controle de custos de atenção à saúde.

Ademais, não há evidência de que os indivíduos terão um incentivo para adotar hábitos saudáveis para reduzirem seus gastos em saúde.

Quando houve controle de custos, como no caso cingapuriano, deveu-se tão somente às pesadas restrições de oferta. Em Cingapura, 58\% dos gastos em saúde são financiados pelo desembolso direto, enquanto as MSA respondem por 8,5\% das despesas.

$\mathrm{O}$ produto cresce hoje nos EUA ante a pressão altista dos gastos em saúde, que, no cenário recessivo instalado na esteira da grande crise financeira de 2008, fez com que empresários buscassem alternativas mais baratas para o financiamento da saúde dos trabalhadores, figurando, entre elas, as MSA, denominadas Health Savings Accounts naquele país. Críticos das MSA argumentam que o produto permite aos empregadores transferir custos de benefícios de saúde para os trabalhadores.

As MSA custam entre $15 \%$ e $20 \%$ menos do que um seguro compreensivo, para fins de adesão ao produto. Isso, graças aos desembolsos diretos, não quantificáveis pelo seu caráter individual, específico. No entanto, a inflação médica no produto equivale à inflação geral dos seguros-saúde.

Alguns observadores apontam que a expansão das MSA poderá levar a aumentos nos preços dos seguros tradicionais, de cobertura compreensiva, face ao 
desmantelamento do pacto intergeracional. É consabido que as saídas de jovens e saudáveis - a base contributiva - das carteiras de planos tradicionais geram incremento no custo da carteira remanescente de forma exponencial, e, no caso das populaçóes em processo de envelhecimento, isso poderá levar a uma elevação das despesas assistenciais desse grupo.

No Brasil, diante do estágio regulatório concernente às coberturas previstas no rol mínimo de procedimentos para as operadoras e seguradoras de saúde, a implantação das MSA encontraria uma barreira legal. O Artigo 10 da Lei no 9.656 instituiu, no âmbito da saúde suplementar, o plano-referência de assistência à saúde, sem limite financeiro para cobertura dos eventos em saúde, que corresponde a um rol mínimo de procedimentos.
Assim, na medida em que, segundo a lei, a amplitude das coberturas será definida por normas da regulação setorial, um seguro com franquias, com característica de restriçôes de acesso e, portanto, com admissibilidade de negativas de cobertura, não poderia prosperar sem uma revisão no parlamento.

$\mathrm{Na}$ hipótese de admissibilidade do produto, tal feito poderia pressionar ainda mais o orçamento público. Seria esperado que uma massa de clientes do produto MSA evitasse despender dos seus saldos nas mesmas MSA para obter atendimento gratuito no Sistema Único de Saúde (SUS). E, ao serem instadas a ressarcirem ao erário, as operadoras poderiam alegar nulidade da ação, tendo em vista que tais procedimentos não estariam respaldados no rol dos relacionados às MSA, dada a restrição de acesso imposta pelas franquias.

\section{Referências}

BARR, M. D. Medical Savings Accounts in Singapore: a critical inquiry. Journal of Health Politics, Policy and Law, St. Louis, v. 26, n. 4, aug. 2001. Duke University Press, USA, 2001.

CANNON, M. F. Health Savings Accounts: do the critics have a point? Washington, DC: Cato Institute, 2006. 28p. (Policy Analysis Series, n. 569).

GOODMAN, J. C. Medical Savings Accounts: an idea whose time has come. In: ARNETT, G. M. (org.) Empowering health care consumers through tax reform. Michigan: The University of Michigan Press, 1996. p.

GOODMAN, J; MUSGRAVE, G. L. Controlling health care costs with Medical Savings Accounts. Washington: National Center for Policy Analysis, 1992. 40 p. (Policy Report, n. 168).

HANVORAVONGCHAl, P. Medical Savings Accounts: lessons learned from limited international experience. Geneva: World Health Organization, 2002. 53 p. (Discussion paper, n. 3). Disponível em: <http://www. docstoc.com/docs/17643244/Medical-Savings-Accounts> Acesso em: 10 jun. 2011.

$\mathrm{HSIAO}$, W. C. Behind the ideology and theory: what is the empirical evidence for Medical Savings Accounts? Journal of Health Politics, Policy and Law, St. Louis, v. 26, n. 4, p., aug. 2001.
KRUGMAN, P. Patients Are Not Consumers. New York: New York Times, 2011. Disponível em: <http://www.nytimes.com/2011/04/22/ opinion/22krugman.html?partner=rssnyt\&emc=RSS>. Acesso em: 02 maio 2011.

SALLES DIAS FILHO, P. P. Encarando um mundo instável e incerto: experiências regulatórias face aos riscos relativos aos seguros saúde. 2010. 196f. Dissertação (Mestrado em Saúde Coletiva) Instituto de Medicina Social, Universidade do Estado do Rio de Janeiro, Rio de Janeiro, 2010

SCHELKLE, W. Collapsing worlds and varieties of welfare capitalism: how to step out of Weber's long shadow. Oxford: Oxford Centre for the Study of Inequality and Democracy, 2008. 27p.

SCHRAMM, F. R. A Saúde é um Direito ou um Dever? Prolegômenos a uma autocrítica da saúde pública: Considerações sobre vulnerabilidade, vulneração, proteção, biopolítica e hospitalidade. 2006. Disponível em: <http://www6.ensp.fiocruz.br/repositorio/ resource/357084>. Acesso em: 10 jun. 2011.

SCHREYÖGG, J. Demographic development and moral hazard: health insurance with medical savings accounts. The Geneva Papers on Risk and Insurance, Oxford, v. 29, n. 4, p. 689-704, oct. 2004. 
SHORTT, S. E. D. Medical Savings Accounts in publicly funded health care systems: enthusiasm versus evidence. Canadian Medical Association Journal, Ottawa, v. 167, n. 2, p. 159-162, 2002.
TOWERS-PERRIN. Health Care Cost Survey. 2008. Disponível em: $<$ http://www.towersperrin.com/tp/getwebcachedoc?webc=HRS/ USA/2008/200801/hccs_2008.pdf> Acesso em: 25 abr. 2011.

Recebido para publicação em Dezembro/2011

Versão definitiva em Agosto/2012

Suporte financeiro: não houve

Conflito de interesse: inexistente 